\title{
FTIR microscopy contribution for comprehension of degradation mechanisms in PLA-based implantable medical devices
}

Adrien Leroy, 1

Sofia Ribeiro, 2

Carole Grossiord, 3

Antoine Alves, 4

Robert H. Vestberg, 2

Vincent Salles, 1

Céline Brunon, 3

Kerstin Gritsch, 5

Brigitte Grosgogeat, 5

Yves Bayon, $2 \square$

Phone +33474089000

Emailyves.bayon@medtronic.com

1 Laboratoire des Multimatériaux et Interfaces, UMR 5615 CNRS-Université Lyon 1, Université de Lyon, 43 bd du 11 Novembre 1918, Villeurbanne, Cedex 69622 France

2 Medtronic-Sofradim Production, 116 Avenue du Formans, Trévoux, 01600 France

3 Science et Surface, 64 Chemin des Mouilles, Écully, 69130 France

4 NAMSA France, 115 Chemin de l'Islon, Chasse-sur-Rhône, 38670 France

5 Laboratoire des Multimatériaux et Interfaces UMR CNRS 5615, UFR Odontologie, Université Lyon 1, Université de Lyon, Lyon, 69008 France 
6 Present Address: Institut de Science des Matériaux de Mulhouse (IS2M), UMR CNRS 7361-UHA, 15 rue Jean Starcky, Mulhouse, 68057 France

\section{Abstract}

The integration and evolution of implantable medical devices made of bioresorbable polymers and used for temporary biomedical applications are crucial criteria in the success of a therapy and means of follow-up after implantation are needed. The objective of this work is to develop and evaluate a method based on microscopic Fourier Transform InfraRed spectroscopy (FTIR) mappings to monitor the degradation of such polymers on tissue explant sections, after implantation. This technique provided information on their location and on both their composition and crystallinity, which is directly linked to their state of degradation induced predominantly by chain scissions. An in vitro study was first performed on poly(L-lactic acid) (PLLA) meshes to validate the procedure and the assumption that changes observed on FTIR spectra are indeed a consequence of degradation. Then, mappings of in vivo degraded PLLA meshes were realized to follow up their degradation and to better visualize their degradation mechanisms. This work further warrants its translation to medical implants made of copolymers of lactic acid and to other polyesters.

\section{Graphical Abstract}

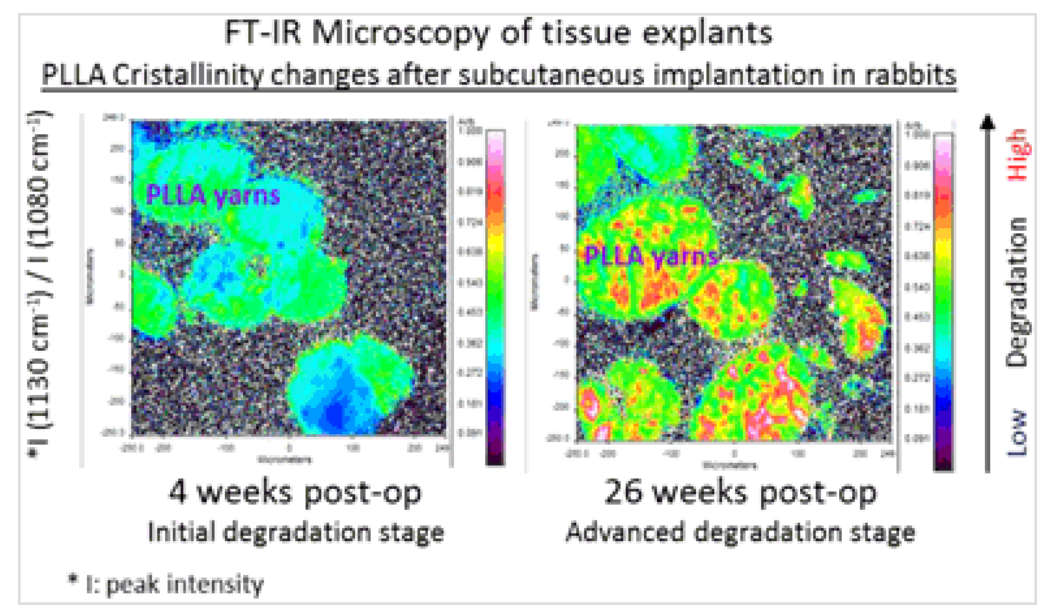

Abbreviations

FTIR Fourier Transform InfraRed spectroscopy

PLLA Poly(L-lactid acid)

PLA Polylactic acid 
THF Tetrahydrofuran

\section{LA Lactide}

GA Glycolide

TLC Trimethylene carbonate

$\mathrm{M}_{\mathrm{n}} \quad$ Number average molecular weight

$\mathrm{M}_{\mathrm{w}} \quad$ Mass average molecular weight

Đ Dispersity

SEC Size Exclusion Chromatography

DSC Differential Scanning Calorimetry

$\mathrm{T}_{\mathrm{g}} \quad$ Glass transition temperature

$\mathrm{T}_{\mathrm{m}} \quad$ Melting temperature

$X_{c} \quad$ Degree of crystallinity

ATR Attenuated Total Refection

MCT Mercury-Cadmium-Telluride

PCA Principal Component Analysis

ECM Extracellular matrix

OM Optical microscopy

\section{Introduction}

Polylactic acid (PLA) is an aliphatic polyester that can be synthesized from lactic acid or by ring-opening polymerization of lactide. It has two optical isomers, L- and D-isomers, the first being the natural occurring polymer. Poly(Llactic) acid (PLLA) is a semi-crystalline polymer with a glass transition temperature of $60-65^{\circ} \mathrm{C}$ and a melting temperature approximately $175^{\circ} \mathrm{C}[1,2$, 3]. PLLA can have different crystal structures. The most common structure is $\alpha$ form which is produced by polymer melt or solution crystallization. Another form is the $\beta$ form which comes from crystallization at high temperature under high draw ratios as for example in fiber spinning [4].

PLLA has attracted huge interest from the biomedical and pharmaceutical fields and has been massively used as a material in surgical operations, tissue regeneration and drug delivery systems, for decades now [5]. Besides being considered as a "green polymer", PLLA's great advantage is that it is degraded, mostly by hydrolysis $[6,7]$. In tissue engineering applications it is vital to fully understand the degradation process of the biomaterial in question, since the coordination of molar and gravimetric mass losses and tissue healing determines how successful the tissue repair is. The hydrolytic degradation of PLA occurs by 
bulk erosion process where diffusion-reaction mechanisms are in play [8]. The human body metabolizes this polymer by hydrolysis into lactic acid, which is further broken down to water and carbon dioxide and eventually excreted by the organism $[1,2]$. This type of polymer has a degradation rate of $50 \%$ in about 1 to 2 years [5].

It has been previously reported many studies about PLA degradation in vitro, reporting the monitoring of parameters such as crystallinity $[9,10,11]$, temperature $[9,12,13,14]$, time $[8,15,16,17,18]$ and $\mathrm{pH}[12,19,20,21,22]$. The degradation products of PLA materials cause a drop of $\mathrm{pH}$, contributing to a faster degradation and, when implanted, a locally inflammatory response persisting until the full disappearance of the materials [23].

Most studies on PLLA hydrolysis are performed at $37^{\circ} \mathrm{C}$ (standard temperature for in vitro assays). However, some studies present the time-temperature equivalent relationship degradation process of PLLA, at temperatures up to 90 ${ }^{\circ} \mathrm{C}$ [24]. Since PLLA takes a long time to completely degrade in real aging conditions (i.e. at $37^{\circ} \mathrm{C}$ ), accelerated degradation can generate other PLLA materials, in about a week, which are good representatives of the aging process, occurring at physiological temperature.

Crystallization in biodegradable polymers is a vital process due to its influence over physical, mechanical and degradability properties [24]. There are many studies on the crystallization kinetics of PLLA using techniques such as DSC, NMR and FTIR [9, 14, 16, 24, 25, 26]. Compared to other techniques, FTIR spectroscopy shows advantages in the analysis of the polymer crystallinity. FTIR is a non-destructive fast technique, hence suitable for a rapid determination of crystallinity and crystal structure. However this technique presents also drawbacks such as making the correct identification of bands to the amorphous and crystalline content, and find the accurate absorption coefficient ratio between amorphous and crystal phases [16].

FTIR microscopy should also present key advantages in confirming the presence or absence of residual materials by their chemical nature and IR absorption profile. It should be particularly useful at advanced stages of degradation, associated with the fragmentation and possible migration of the implanted materials. The aim of this study is to develop a new imaging technique to identify the implanted material and to track the degradation of resorbable polymers in vivo. The crystallinity of the material was observed using FTIR microscopy analysis, giving the characteristic spectra of PLLA at different degradation levels after aging at $90{ }^{\circ} \mathrm{C}$. The in vitro degradation profile was analyzed and then the imaging technique was then translated to in vivo studies 
with analysis on fixed tissue explant sections. Finally, the potential of this FTIR imaging technique has been applied to the degradation of other resorbable polyesters.

\section{Materials and methods}

\subsection{Materials}

Tetrahydrofuran (99.9\%) (THF) was purchased from Sigma Aldrich and Phosphate-Buffered Saline (PBS, pH 7.4) from ThermoFisher Scientific (Gibco).

Two kinds of bioresorbable hernia meshes were used for the degradation studies. Poly(L-lactide) (PLLA) meshes (Sofradim Production, France) were used for both in vitro and in vivo degradation studies and TIGR ${ }^{\circledR}$ Matrix Surgical Meshes (Novus Scientific, Sweden) (thereafter called TIGR mesh) were only used for the in vivo study. TIGR mesh is knitted from two different synthetic resorbable fibers: the first kind of fibers is made of a copolymer of lactide (LA), glycolide (GA) and trimethylene carbonate (TMC) and the second one is made of a copolymer of LA and TMC.

\subsection{Characterizations}

\subsubsection{Molecular weight}

The number average molecular weight $\left(\mathrm{M}_{\mathrm{n}}\right)$, mass average molecular weight

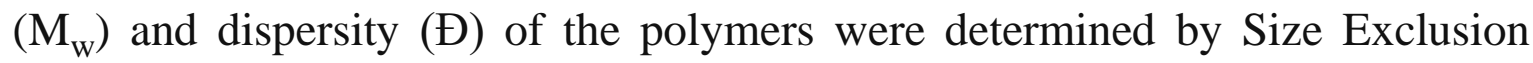
Chromatography (SEC) using a Waters Aquity UPLC fitted with two Shodex GPC KF-805L columns, a Shodex GPC KF-G guard column and Wyatt refractive index and multiangle light scattering detectors. The mobile phase was THF, flowing at $1 \mathrm{~mL} \mathrm{~min}^{-1}$. For each tested polymer, three samples were analyzed with two injections $(3.5 \mathrm{mg} / \mathrm{mL})$.

\subsubsection{Differential Scanning Calorimetry (DSC)}

DSC measurements were carried out on a Mettler Toledo DSC thermal analyzer. For each reference, four samples $(5-6 \mathrm{mg})$ were submitted to a heating scan to $200{ }^{\circ} \mathrm{C}\left(10^{\circ} \mathrm{C} / \mathrm{min}\right)$, a cooling scan to $0^{\circ} \mathrm{C}\left(10^{\circ} \mathrm{C} / \mathrm{min}\right)$ and a second heating scan to $200^{\circ} \mathrm{C}\left(10^{\circ} \mathrm{C} / \mathrm{min}\right)$. Glass transition temperature $\left(\mathrm{T}_{\mathrm{g}}\right)$, melting temperature $\left(\mathrm{T}_{\mathrm{m}}\right)$ and degree of crystallinity $\left(\mathrm{X}_{\mathrm{c}}\right)$ were determined from the second heating ramp. A reference enthalpy of melting of $93.1 \mathrm{~J} / \mathrm{g}$ was used to calculate the crystallinity of PLA [27].

\subsubsection{Fourier Transform InfraRed Spectroscopy (FTIR)}


FTIR analyses were performed, using a Perkin-Elmer Spotlight 400 microspectrometer, on polymer samples obtained from the in vitro study and on the tissue sections obtained from in vivo experiments. FTIR mapping was performed in Attenuated Total Refection (ATR) mode using the ATR-imaging accessory with a germanium crystal. The scanned area was $400 \times 400 \mu \mathrm{m}^{2}$ (lateral resolution of $1.56 \mu \mathrm{m}$ ). The MCT (Mercury-Cadmium-Telluride) detector covered the range from 720 to $4000 \mathrm{~cm}^{-1}$ with a spectral resolution of $8 \mathrm{~cm}^{-1}$. Principal Component Analysis (PCA) calculation was applied to raw FTIR images using SpectrumIMAGE software from Perkin-Elmer. The calculation extracts from each pixel of the image the first 8 components showing largest variance. Two PCA calculations were used in this study: PCA 1 considers component \#1 (in red, corresponding to PLLA spectrum), component \#2 (in green, corresponding to the glass substrate supporting the histological crosssection) and component \#3 (in blue, corresponding to TMC contribution, only visible in TIGR mesh samples). PCA 2 (used only for TIGR mesh samples) considers component \#1 (in red, corresponding to PLLA spectrum), component \#3 (in green, corresponding to TMC contribution) and component \#4 (in blue, corresponding to protein contribution). Maps thereafter labeled "PCA" correspond to PCA 1 calculation maps.

\subsection{In vitro degradation study}

For this degradation study, polymer samples $\left(15 \times 5 \mathrm{~cm}^{2}\right.$ PLLA meshes $)$ were initially weighed and placed in PBS (two meshes in $100 \mathrm{~mL}$ ) at $90^{\circ} \mathrm{C}$. The PBS was changed every one or 2 weeks. At each scheduled time point, samples were removed from PBS and rinsed 3 times with distilled water. After at least $12 \mathrm{~h}$ of drying under vacuum, they were weighed to calculate the gravimetric mass loss, analyzed by SEC and DSC, and FTIR spectra were finally obtained.

\subsection{Preparation of pre-degraded samples for in vivo degradation study}

Both PLLA and TIGR meshes undergo slow degradation by bulk hydrolysis and are expected to be completely absorbed 36 months after implantation [28]. The assessment of the entire in vivo degradation process of such devices therefore requires a long follow-up. To decrease this follow-up duration, samples were submitted to an in vitro pre-degradation process before implantation. Based on the data obtained from in vitro degradation studies, some samples $\left(2 \times 1.5 \mathrm{~cm}^{2}\right)$ were pre-degraded in PBS at $50{ }^{\circ} \mathrm{C}$ so that we have samples in three different degradation states : non pre-degraded, partially pre-degraded and highly predegraded. The properties of these samples before implantation are listed in Table 1. All samples were provided as sterile meshes ready to implant $(2 \times 1.5$ 
$\mathrm{cm}^{2}$ ) except highly pre-degraded PLLA samples which were provided as sterile moistened particulates $(15-20 \mathrm{mg})$ corresponding to residues of meshes $(2 \times 1.5$ $\mathrm{cm}^{2}$ ) recovered after a few seconds of centrifugation at $1000 \mathrm{rpm}$.

Table 1

Properties of polymer samples used for in vivo degradation study before implantation

\begin{tabular}{|l|l|l||l|}
\hline \multicolumn{1}{|c|}{ Sample } & Reference & $\begin{array}{c}\text { Equivalent degradation time } \\
\text { at } 7^{\circ} \mathbf{C} \text { (weeks) }\end{array}$ & $\begin{array}{c}\text { Mass } \\
\text { retention } \\
(\%)\end{array}$ \\
\hline $\begin{array}{l}\text { Non pre-degraded } \\
\text { PLLA mesh }\end{array}$ & ${ }_{0}$ PLLA & 0 & 100 \\
\hline $\begin{array}{l}\text { Partially pre-degraded } \\
\text { PLLA mesh }\end{array}$ & ${ }_{1}$ PLLA & 60 & 100 \\
\hline $\begin{array}{l}\text { Highly pre-degraded } \\
\text { PLLA mesh }\end{array}$ & ${ }_{2}$ PLLA & 120 & 59 \\
\hline $\begin{array}{l}\text { Non pre-degraded } \\
\text { TIGR mesh }\end{array}$ & ${ }_{0}$ TIGR & 0 & 100 \\
\hline $\begin{array}{l}\text { Partially pre-degraded } \\
\text { TIGR mesh }\end{array}$ & ${ }_{1}$ TIGR & 12 & 76 \\
\hline $\begin{array}{l}\text { Highly pre-degraded } \\
\text { TIGR mesh }\end{array}$ & ${ }_{2}$ TIGR & 80 & 43 \\
\hline
\end{tabular}

\subsection{In vivo degradation study}

\subsubsection{Animals}

In order to study the integration and the degradation of bioresorbable medical devices, an in vivo study was carried out. 18 New Zealand White male rabbits (Oryctolagus cuniculus; Charles River France) (3.0-3.8 kg) were included in this study.

The study was performed in strict accordance with European Directive 2010/63/UE and European Convention of the Council of Europe ETS123). All procedures were performed at NAMSA, (Chasse/Rhône, France).

This study was approved by the local NAMSA Ethical Committee (NAMSA is an accredited facility registered with the French Department of Agriculture for animal housing, care and investigations).

\subsubsection{Experimental design}


Each rabbit received 8 subcutaneous implants: 4 PLLA test meshes and 4 TIGR control meshes. The follow-up period was 4,26 and 52 weeks $(n=6$ animals per time-period). Both PLLA and TIGR meshes were implanted in 3 configurations: original (non pre-degraded), partially pre-degraded and highly pre-degraded state (Table 1).

\subsubsection{Surgical procedure}

Buprenorphine (Buprecare ${ }^{\circledR}$, Axience, $0.02 \mathrm{mg} / \mathrm{kg}$ ) was administered subcutaneously prior to surgery. Rabbits were anesthetized by intramuscular injection of a mixture of ketamine hydrochloride (Ketamine 1000, Virbac, 20 $\mathrm{mg} / \mathrm{kg}$ ) and xylazine (Rompun ${ }^{\circledR}$, Bayer, $5 \mathrm{mg} / \mathrm{kg}$ ). When requested, anesthesia was maintained by inhalation of an $\mathrm{O}_{2}$-isoflurane mixture (IsoFlo ${ }^{\circledR}$, Axience, 0.5$5 \%$ ). After the anesthetic has taken effect, sufficiently large areas of the rabbits were shaved using an electric clipper with a fine comb, avoiding any cutaneous trauma. The shaved area was cleaned with povidone iodine (Vetedine ${ }^{\circledR}$ Savon, Vetoquinol), wiped with $70 \%$ isopropyl alcohol, painted with povidone iodine solution (Vetedine ${ }^{\circledR}$ Solution, Vetoquinol) and draped. Eight incisions (four per side) large enough to accommodate each sample were made through the skin and parallel to the vertebral column (approximately $1.5 \mathrm{~cm}$ from the midline, $1.5-2 \mathrm{~cm}$ length). Pockets were formed by blunt dissection in the subcutaneous tissue with a standardized depth (approximately $3.5 \mathrm{~cm}$ ). Before implantation, two non-absorbable stitches (Surgipro ${ }^{\mathrm{TM}}$ II, 4-0, Covidien) were placed approximately $8 \mathrm{~mm}$ above the implanted article and approximately 8 mmbelow the cutaneous incision, in the subcutaneous tissue towards the skin, spaced from approximately $1.5 \mathrm{~cm}$ to locate the articles at termination. Four PLLA or TIGR mesh articles were introduced in the pockets of one side with one article per pocket, articles were placed at appropriately spaced intervals (approximately $2 \mathrm{~cm}$ ). Highly pre-degraded PLLA samples (particulates) were placed in their subcutaneous pockets using a spatula. On the opposite side, four test and control articles were similarly implanted. The skin was closed with stainless steel skin staples and pressure bandages were applied. The rabbits were monitored until recovery from the anesthetic procedure and then returned to their respective cages.

\subsubsection{Termination and histologic preparation}

Four, 26 or 52 weeks after implantation, the designated rabbits were euthanized by intravenous injection of pentobarbital (Dolethal ${ }^{\mathrm{ND}}$, Vetoquinol). The subcutaneous tissues were excised, sampled and flat fixed in $10 \%$ neutralbuffered formalin (NBF). After complete fixation, the tissue explants were dehydrated in alcohol solutions of increasing concentration, cleared in xylene 
and embedded in paraffin. For each sample, two central longitudinal ventrodorsal cross sections were prepared using a microtome $\left(\right.$ MICROM $^{\circledR}$, France). One was used for histological analysis $(4-7 \mu \mathrm{m}$ thick) and one $(9 \mu \mathrm{m}$ thick) was used for FTIR mapping.

\subsubsection{Histology}

Sections were stained by Safranin-Hematoxylin-Eosin and modified Masson's Trichrome.

\subsubsection{FTIR microscopy}

Three different FTIR maps of tissue explant sections $\left(\approx 10 \times 20 \mathrm{~mm}^{2}\right)$ after dewaxing, were processed. Components were identified and colored thanks to Principal Components Analysis (PCA). R2 ratio $\left(1130 / 1080 \mathrm{~cm}^{-1}\right.$ band intensity) and amide I protein $\left(1646 \mathrm{~cm}^{-1}\right)$ were imaged in false colors (low values appear in blue, high values appear in red).

At explantation, parts of the samples where used for SEC analyses. The explanted sample was exposed to a collagenase solution $(1 \mathrm{mg} / \mathrm{ml})$ in $\mathrm{PBS}(\mathrm{pH}=$ 7.4) for $16 \mathrm{~h}$. The samples where then rinsed three times with water and dried under vacuum for $12 \mathrm{~h}$ before SEC analysis.

\section{Results}

\subsection{In vitro degradation of PLLA meshes}

The hydrolytic degradation process of aliphatic polyesters such as PLA or PGA occurs by random scissions of ester bonds within the polymer chains. Since this process may meet slow kinetics, especially for highly crystalline polymers like PLLA, an accelerated degradation protocol was used to study the behavior of our polymers. Indeed, it was calculated that the degradation process would be 496 times faster at $90^{\circ} \mathrm{C}$ than at $37^{\circ} \mathrm{C}$ [29]. At this temperature, the estimated degradation time of our PLLA meshes would be about 1 week (assuming full degradation within 4-5 years). The in vivo degradation is anticipated to be faster, notably at the latest stages, with more susceptibility to be degraded by the polymorphonuclear leukocyte cells by their chemical armors and endocytosis/phagocytosis of fragments [30].

To measure the evolution of FTIR peaks during PLLA degradation, spectra were obtained from non-degraded $(0 \mathrm{~h})$ and degraded $\left(8,24\right.$ and $120 \mathrm{~h}$ at $\left.90^{\circ} \mathrm{C}\right)$ PLLA mesh samples (Table 2, Fig. 1 and Supplementary Fig 1). 
Characteristics of in vitro degraded PLLA meshes

\begin{tabular}{|l|l|l|l|l|}
\hline \multicolumn{1}{|c|}{ Degradation time (hours) } & \multicolumn{1}{|c|}{$\mathbf{0}$} & \multicolumn{1}{|c|}{$\mathbf{8}$} & \multicolumn{1}{|c|}{$\mathbf{2 4}$} & $\mathbf{1 2 0}$ \\
\hline Mn retention (\%) & 100 & 60 & 15 & $<5$ \\
\hline Mass retention (\%) & 100 & $>99$ & $>97.5$ & 70 \\
\hline Crystallinity (\%) & 48 & 54 & 57 & 73 \\
\hline Eq. degradation time at $37^{\circ} \mathrm{C}$ in weeks & 0 & 23 & 71 & 354 \\
\hline
\end{tabular}

\section{Fig. 1}

Evolution of FTIR spectra during PLLA degradation. Spectra were obtained from non-degraded $(0 \mathrm{~h})$ and degraded $\left(8,24\right.$ and $120 \mathrm{~h}$ at $\left.90^{\circ} \mathrm{C}\right)$ PLLA mesh samples. These spectra revealed notably peak shifts and an increase of intensity for bands at 1209 and $1130 \mathrm{~cm}^{-1}$ during degradation. See particularly Fig. 1c
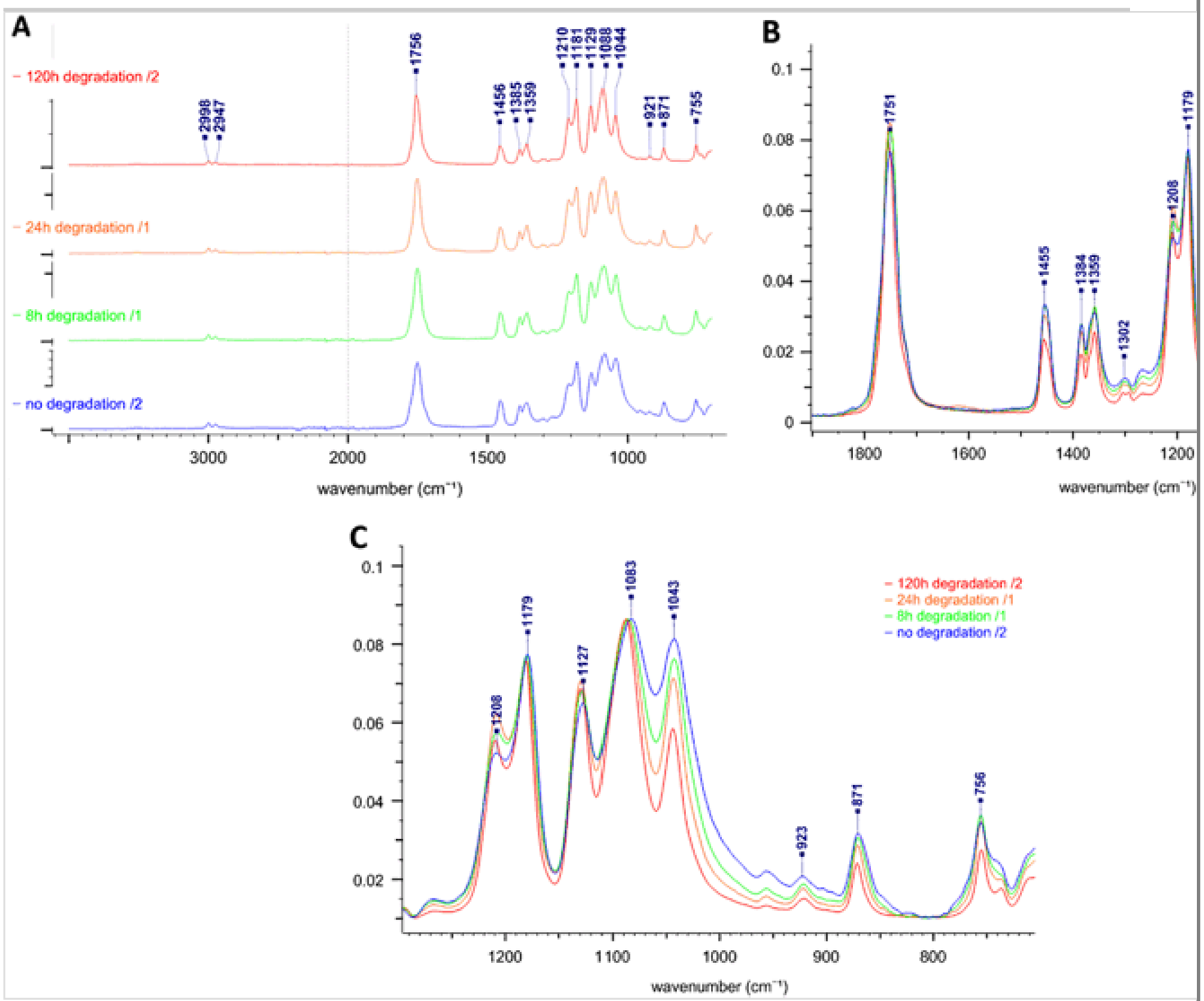

The IR spectra of all PLLA samples, non-degraded and degraded present the common features of PLA polymers formed of L-lactic acid units. In particular, a 
clear peak at $1208 \mathrm{~cm}^{-1}\left(\right.$ vasCOC $\left.+\mathrm{CH}_{3}\right)$, is observed whereas a faint peak is noticed around $1265 \mathrm{~cm}^{-1}(\delta \mathrm{CH}+v \mathrm{COC})$ which is typical of PLLA [30]. It is assumed that all analyzed PLLA samples in their native and degraded states are mostly in the $\alpha$ crystalline configuration. The IR spectra are similar to previously analyzed PLLA, notably with the lack the characteristic band of PLLA $\beta$ at 908 $\mathrm{cm}^{-1}$ [31]. The fact to confirm the homogeneity of the PLLA samples in terms of crystalline structure should facilitate the real contribution of the crystallinity changes occurring during the thermal hydrolytic degradation of the PLLA materials on their IR profile. Indeed, the corresponding spectra revealed peak shifts and an increase of intensity for bands at 1209 and $1130 \mathrm{~cm}^{-1}$ during degradation. These bands are related respectively to the asymmetric $\mathrm{C}-\mathrm{O}-\mathrm{C}$ stretching and asymmetric $\mathrm{CH}_{3}$ rocking vibrations [32]. It was already shown that such changes occurring with aliphatic polyesters could be explained by a change in the polymer crystallinity [16, 32, 33]. In our case, one of the consequences of PLLA degradation is a decrease of its molecular weight caused by chains scissions. Shorter PLLA chains mobility is thus increased, which allows them to reach a more crystalline state, in the $\alpha$ configuration. Based on the literature [7], we assumed that the changes observed for the bands at 1209 and $1130 \mathrm{~cm}^{-1}$ were caused by the increase of PLLA crystallinity and corresponding increase in the amount of $\alpha$ crystals during degradation. Hereby it would be possible to follow the degradation of the polymer by calculating peak intensity ratio differences. Ratios R1 $\left(1209 / 1180 \mathrm{~cm}^{-1}\right.$ band intensity) and R2 $\left(1130 / 1080 \mathrm{~cm}^{-1}\right.$ band intensity) were selected for this study.

To validate this hypothesis, we analyzed two non-degraded PLLA samples which were previously submitted to two different thermal treatments. The first sample was heated from 25 to $220^{\circ} \mathrm{C}\left(10^{\circ} \mathrm{C} / \mathrm{min}\right)$ and slowly cooled to $25^{\circ} \mathrm{C}\left(1{ }^{\circ} \mathrm{C} / \mathrm{min}\right)$ to allow crystallization. The second one was heated from 25 to $220^{\circ} \mathrm{C}(10$ ${ }^{\circ} \mathrm{C} / \mathrm{min}$ ), removed from the oven and immediately immersed in liquid nitrogen to prevent crystallization and reach an amorphous state. After these treatments, both samples were analyzed by DSC: the first sample only exhibited a melting peak $(\Delta \mathrm{H}=-41 \mathrm{~J} / \mathrm{g})$ whereas the second one exhibited a cold crystallization peak $(33 \mathrm{~J} / \mathrm{g}$ ) followed by a melting peak $(-32 \mathrm{~J} / \mathrm{g})$. These results confirmed that the first sample was able to crystallize during the slow cooling step whereas the second one was almost totally amorphous after being quenched. As a consequence, these two samples had different crystallinity rates but had similar chemical compositions.

For both these samples of crystallized and amorphous PLLA as well as for nondegraded $(0 \mathrm{~h})$ and highly degraded $(120 \mathrm{~h})$ PLLA mesh samples, ratios R1 and R2 were calculated (Table 3). Results showed that both ratios were higher with highly degraded PLLA than with non-degraded PLLA. According to our 
hypothesis, this would mean that ratios R1 and R2 increase with the crystallinity of the polymer. This was confirmed by the ratios calculated for crystallized PLLA $(\approx$ non-degraded PLLA) and for amorphous PLLA (<non-degraded PLLA).

\section{Table 3}

R1 and R2 ratios values of PLLA samples, calculated from FTIR spectra. Ratios R1 (1209/ $1180 \mathrm{~cm}^{-1}$ band intensity) and R2 $\left(1130 / 1080 \mathrm{~cm}^{-1}\right.$ band intensity) were selected from FTIR spectra as indicators of PLLA cristallinity

\begin{tabular}{|l|l||l|}
\hline \multicolumn{1}{|c|}{ Polymer } & \multicolumn{1}{c|}{ R1 } & \multicolumn{1}{c|}{ R2 } \\
\hline Amorphous PLLA & 0.06 & 0.19 \\
\hline Crystallized PLLA & 0.12 & 0.28 \\
\hline Non-degraded PLLA & 0.11 & 0.28 \\
\hline highly degraded PLLA & 0.41 & 0.49 \\
\hline
\end{tabular}

\subsection{In vivo degradation of PLLA meshes}

(See Table 1 for the characteristics of the implanted meshes.) To verify that in vitro degradation was representative of the in vivo degradation SEC analyses of in vitro and in vivo degraded samples was performed. The results show that the degradation rate at $+37{ }^{\circ} \mathrm{C}$ is similar $\left(\mathrm{M}_{\mathrm{w}}\right.$ in vitro 26 weeks $=61000 \mathrm{~g} / \mathrm{mol}$ and $\mathrm{M}_{\mathrm{w}}$ in vivo 26 weeks $=57000 \mathrm{~g} / \mathrm{mol}$ ). This confirms that in vitro degradation data can be representative for comparison with in vivo results, with however slightly faster in vivo degradation as anticipated as discussed in the previous section.

As shown in the in vitro degradation study, FTIR ratios R1 and R2 reflect the crystallinity and consequently the degradation of PLLA. To monitor the state and the integration of a medical device made of PLLA, an FTIR ATR-imaging study was realized on tissue sections using three different peak intensities or peak intensity ratios. First, the different components and especially polymer and tissue areas were identified using PCA mapping. Then, the degradation state of the polymer areas was monitored thanks to R1 or R2 ratios. Indeed, R1 ratio mapping showed less accuracy in case of highly degraded fibers surrounded with tissue because of partial interference between bands at $1208 \mathrm{~cm}^{-1}$ of PLLA and $1232 \mathrm{~cm}^{-1}$ of protein. Only R2 pictures were therefore analyzed in this study. Finally, a last mapping was realized at $1646 \mathrm{~cm}^{-1}$ (the amide I protein band) to detect the presence of neo-tissue extracellular matrix (ECM). Color scales for R2 ratio and $1646 \mathrm{~cm}^{-1}$ peak intensity are presented in Supplementary Fig. 2. 
First, ${ }_{0}$ PLLA samples implanted without in vitro pre-degradation were studied after 4 and 52 weeks implantation (Fig. 2). At the earliest stage of degradation, fibers did not seem damaged and were still easily visible by optical microscopy $(\mathrm{OM})$. PCA mapping allowed even easier identification of the polymer within the tissue section and highlighted the fibers' structure conservation. On the other hand, R2 ratio mapping did not evidence important differences in the degradation state within the fibers. Slightly more crystalline areas could be seen along the outer edge of the fibers as well as in the middle of one of them but these differences could not be considered as major ones. After 4 weeks, degradation therefore seemed to have not visibly started. However, amide I protein mapping revealed early ECM deposition at the fibers interface.

\section{Fig. 2}

FTIR microscopy of non-pre-degraded PLLA meshes ( ${ }_{0}$ PLLA) explants, at 4 and 52 weeks after subcutaneous implantation in rabbits. The intensities of R2 ratio, a degradation indicator based on increased crystallinity, and the amide I protein band is represented in false colors with a gradient from dark blue (low intensity) to hot red (high intensity). OM Optical microscopy, PCA Principal Component Analysis, $\mathrm{R} 2$ ratio: $1130 / 1080 \mathrm{~cm}^{-1}$ band intensity; Amide I protein band at $1646 \mathrm{~cm}^{-1}$
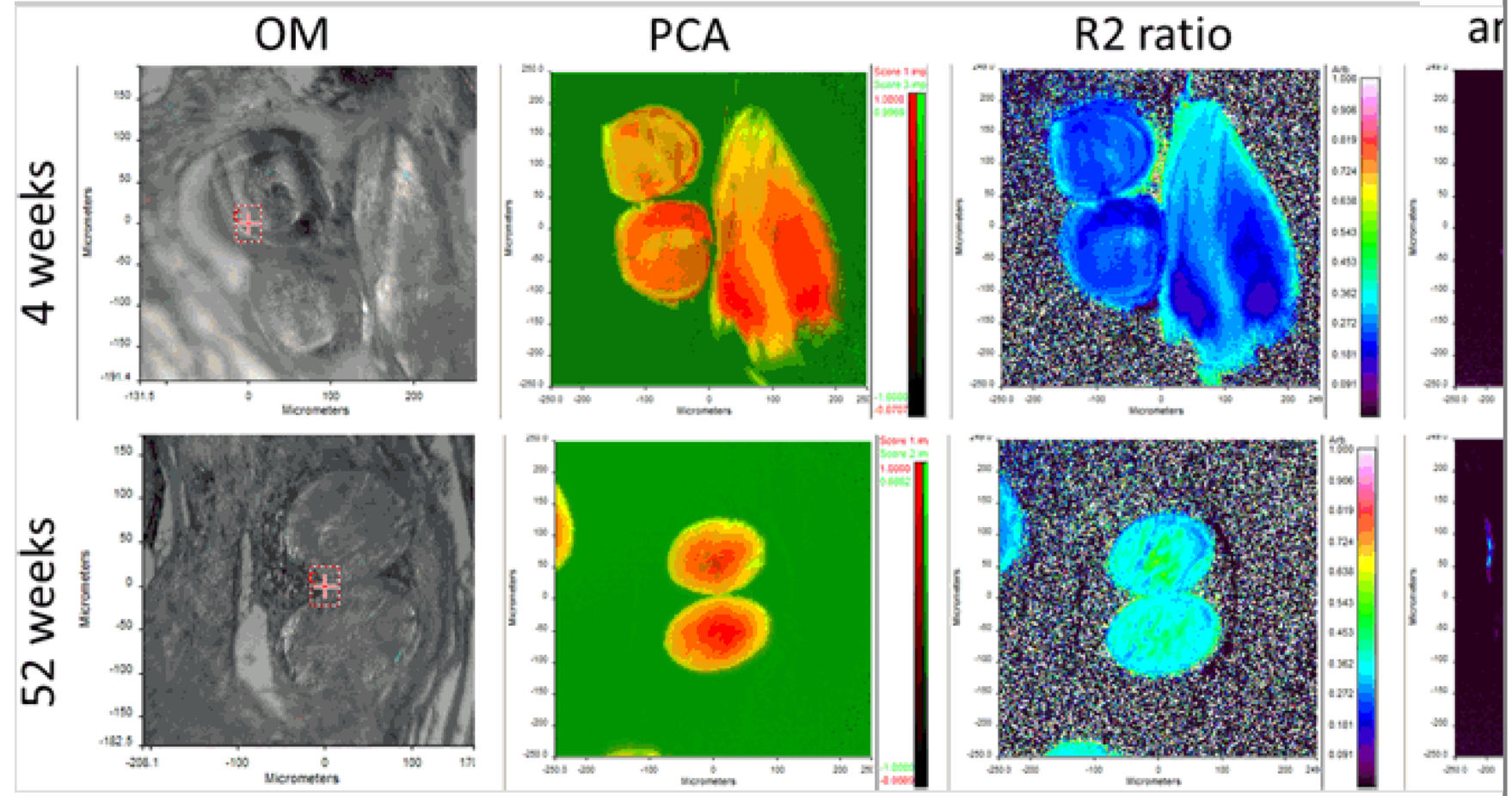

Fifty two weeks after implantation, it was still easy to locate PLLA fibers on both OM pictures and PCA maps and no material breaks or splits could be noticed. This time, however, a crystallinity gradient was observed on the R2 ratio map: a more crystalline (meaning more degraded) area appeared in the central part of each fiber. Even though these differences were still weak, they were in accordance with the current hypotheses on PLLA degradation 
mechanism. Indeed, PLLA is known to undergo bulk degradation by hydrolytic scissions of ester bonds in the polymer chains. This phenomenon is accelerated in the core of the material by the increasing presence of carboxylic acid-ended oligomers generated by the chain scissions which are not able to diffuse out of the material. As a consequence, these oligomers have an autocatalytic action and cause faster degradation in the inner part of the polymer device. Observations on the $\mathrm{R} 2$ ratio map after 52 weeks suggested that the PLLA fibers were at the beginning of this process. Besides, an ECM deposition could once again be observed at the interface of the fibers.

To simulate longer times of degradation, pre-degraded ${ }_{1}$ PLLA samples were then studied 4, 26 and 52 weeks after implantation (Fig. 3). After 4 weeks, location of the fibers was still possible by OM but some areas seemed damaged and some parts were more difficult to distinguish from the surroundung tissues. PCA maps also revealed both undamaged and partially fragmented fibers, suggesting that the samples were actually in a more advanced degradation state than ${ }_{0}$ PLLA samples 52 weeks after implantation. R2 ratio mapping also showed an increased overall crystallinity of this ${ }_{1}$ PLLA sample after 4 weeks compared to ${ }_{0}$ PLLA after 52 weeks. However, R2 ratio mapping showed unexpected results since the faster inner degradation could not be observed any more. Since the samples have been pre-degraded at $90^{\circ} \mathrm{C}$ it is possible that the the degradation products can diffuse more easily when degrading at temperatures higher than the glass transition temperature $\left(\mathrm{Tg}=50-60^{\circ} \mathrm{C}\right)$. In addition, the acidification of the degradation medium over time could also mask the autocatalytic effect. After implantation, the autocatalysis phenomenon is probably too limited after such a short in vivo degradation time (autocatalysis effect was not observed for ${ }_{0}$ PLLA samples after 4 weeks either). Structure damaging of the fibers could also distort FTIR mapping and generate unreliable results. As regards tissue colonization, amide I protein band mapping showed ECM deposition similar to that described for the previous samples at the interface of the fibers.

\section{Fig. 3}

FTIR microscopy of slightly pre-degraded PLLA meshes ( ${ }_{1}$ PLLA) explants, at 4, 26 and 52 weeks after subcutaneous implantation, in rabbits. Legends are the same as for Fig. 2 

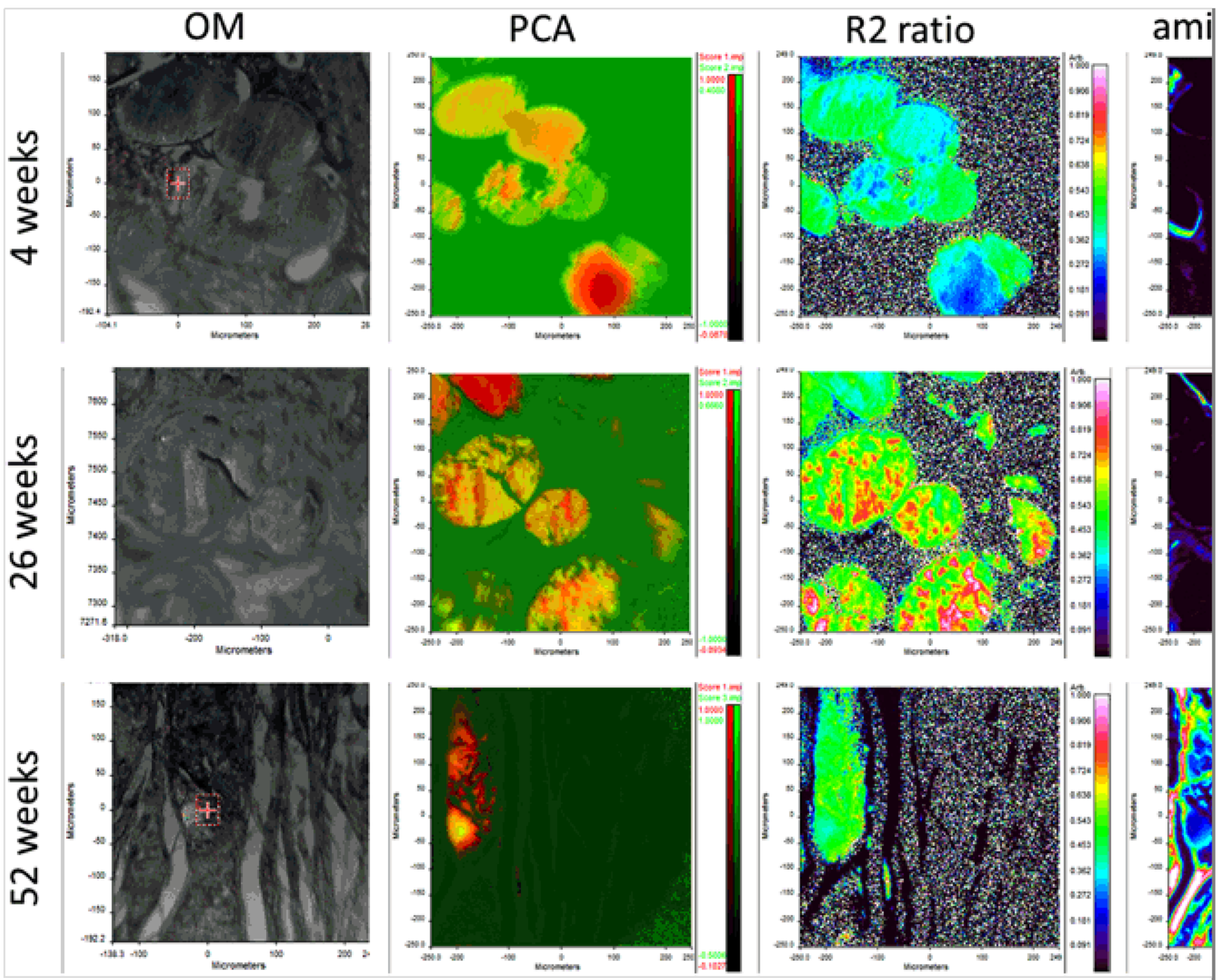

After 26 weeks, OM pictures showed damaged samples with the appearance of cracks within the fibers, making them difficult to locate compared to all the previous samples. In this context, the use of PCA mapping proved to be very useful to precisely locate the polymer in the tissue section. It also clearly evidenced the presence of cracks in the material, which were particularly important since they were not visible on $\mathrm{R} 2$ ratio maps. Contrary to what was observed in ${ }_{1}$ PLLA samples after 4 weeks, these maps revealed many highly degraded areas in the core of the fibers after 26 weeks. The overall degradation polymer in a more advanced state than after 4 weeks and the autocatalysis degradation areas is observed again. Interestingly, where cracks appeared on the PCA maps, R2 ratio mapping sometimes seemed to display low-degraded polymer areas. These differences confirmed that material damaging can cause misinterpretations and proved that $\mathrm{R} 2$ ratio mapping needs to be used and interpreted carefully and completed with other information to be reliable. Concerning the tissue growth, ECM deposition could once again be noticed around the fibers thanks to protein mapping. The ECM areas however seemed slightly wider than they were before, showing the integration of the device within the host tissues. 
Fifty two weeks after implantation, samples were so fragmented that it became very difficult or even impossible to recognize ${ }_{1}$ PLLA residues in the tissue section by OM. As for 26 weeks explants, PCA mapping was necessary to locate the polymer and confirmed the high fragmentation of the material. R2 ratio mapping pictures proved that they should not be used alone for interpretation. The many cracks observed with PCA mapping were indeed not visible with R2 ratio mapping. Moreover, the material seemed to be homogeneously crystalline and less degraded than after 26 weeks, which is not coherent with the degradation mechanism of PLLA. All these inconsistencies could be explained thanks to the last FTIR maps. Indeed, protein mapping revealed an extensive presence of ECM all over the tissue section, including within the PLLA residues. This showed that, at this stage, the neo-tissue colonization may make the R2 ratio mapping provide wrong information and lead to misinterpretations concerning the degradation state of the polymer if it is not correlated with other FTIR mappings.

Finally, ${ }_{2}$ PLLA explants were studied to evaluate the evolution of a highly predegraded sample (Fig. 4). On the one hand, OM and PCA maps observations 26 weeks after implantation were quite similar to those of ${ }_{1}$ PLLA samples after the same in vivo degradation time. Indeed, the fibers were still visible but had suffered important damages. On the other hand, R2 ratio maps seemed to show that ${ }_{2}$ PLLA was in a lower degradation state than ${ }_{1}$ PLLA was at the same moment. Likewise it was observed for ${ }_{1}$ PLLA after 52 weeks, protein mapping of ${ }_{2}$ PLLA after 26 weeks revealed the presence of ECM around the fibers but also, to a lesser extent, within the material, which induced this incorrect information on $\mathrm{R} 2$ ratio maps. Once again, it was clear that $\mathrm{R} 2$ ratio maps had to be analyzed with caution and that information provided by the other FTIR mappings had to be taken in account for reliable interpretation.

\section{Fig. 4}

FTIR microscopy of highly pre-degraded PLLA meshes (2 2 PLLA) explants, at 26 weeks, after subcutaneous implantation, in rabbits. Legends are the same as for Fig. 2
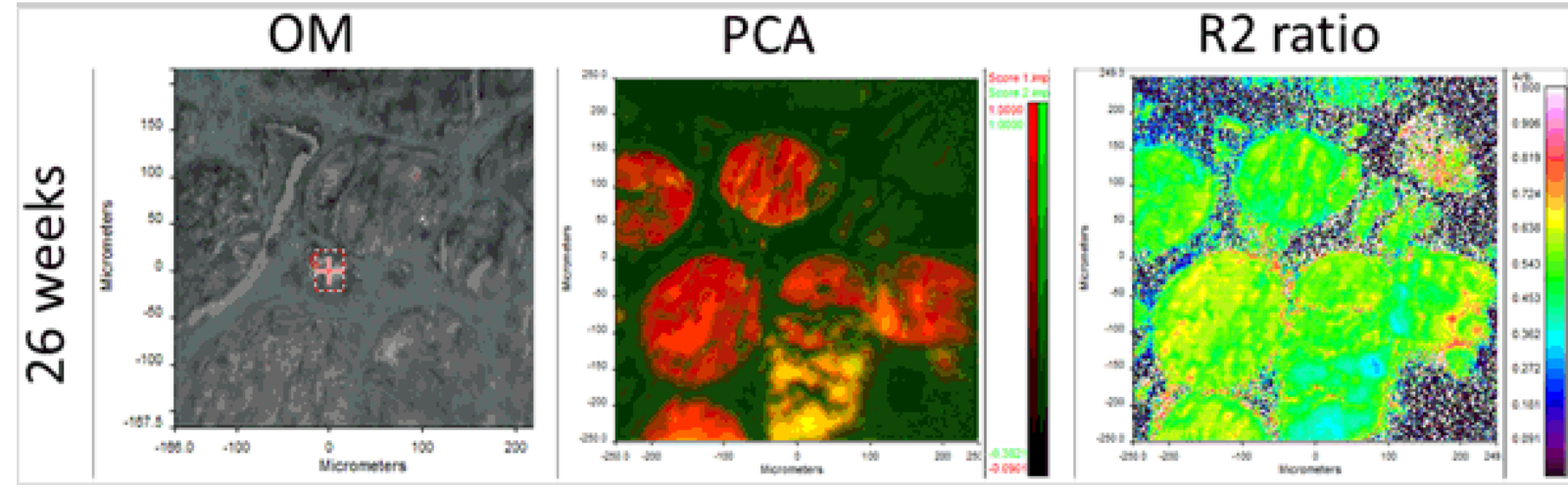
Tissue sections of ${ }_{2} \mathrm{PLLA}$ after 52 weeks are not presented in this study since the material was so degraded that yarn fragmentation, cell infiltration and ECM deposition made degradation monitoring impossible (situation close to that of ${ }_{1}$ PLLA 52 weeks after implantation).

This first in vivo study proved that FTIR mapping was a useful and efficient technique to identify the implanted material and monitor the degradation and the resorption of PLLA medical device after implantation. It also exhibited the limits of this characterization method.

\subsection{In vivo degradation of TIGR meshes}

After demonstrating the feasability of locating PLLA fibers in tissue sections and monitoring their degradation thanks to FTIR mapping, we got interested in the possibility of applying the same procedure to other degradable polymers. Attention was focused on TIGR meshes, whose fast resorbing (copolymer of GA with small amounts of LA and TMC) and slow resorbing (copolymer of LA with small amounts of TMC) multifilament fibers are both described as degrading by bulk hydrolysis [34]. As for the PLLA samples, some TIGR mesh were submitted to an in vitro pre-degradation step before implantation (Table 3).

First, a mapping test was performed on non pre-degraded samples ( ${ }_{0}$ TIGR) after 4 weeks of in vivo degradation (Fig. 5). At this early degradation stage, OM pictures still revealed the presence of the two kinds of fibers (of two different sizes). By performing the same PCA treatment as for PLLA (PCA 1), it was possible to identify the different components of the section. The presence of LA units in slow resorbing fibers was still highlighted by a yellow to red coloration whereas the fast resorbing fibers were located by TMC spectrum correspondance and appeared in blue. Another PCA treatment (PCA 2) allowed even easier location of PGA-based fibers (colored in green) and brought to light a very early fracturation phenomenon within this material, suggesting that these fibers would indeed reach full resorption after a short time. Interestingly, it should be noticed that this PCA treatment also emphasized a third component (colored in blue) which could be identified as neo-tissue ECM thanks to amide I protein mapping. $\mathrm{R} 1$ and $\mathrm{R} 2$ ratios mapping were also performed on the tissue sections and seemed to allow degradation monitoring for slow resorbing fibers. On the contrary, PGA-based polymer was not visible on these maps since the peaks used for R1 and R2 ratios calculation were not present on this polymer's FTIR spectrum at this stage due to the high GA content (Supplementary Fig. 3), thus preventing any degradation monitoring for this material (at least with these ratios). In such case of multi-material degradable device implantation, PCA 2 
treatment thus appeared to be a very efficient tool to locate the different components and to follow their resorption through time. The resolution of obtained images was even sufficient to distinguish individual fibers. However, $\mathrm{R} 1$ or $\mathrm{R} 2$ ratio mapping could be employed to follow crystallinity and degradation states only for the slow resorbing fibers made of PLA-PTMC copolymer.

\section{Fig. 5}

FTIR microscopy of non-pre-degraded TIGR mesh (oTIGR) explants, at 4 weeks, after subcutaneous implantation, in rabbits. PCA1 \& PCA2 enabled the differentiation of slow resorbing yarns (copolymer of TMC, lactic acid; small diameter yarns, colored in orange or red) from fast resorbing yarns (copolymer of TMC, lactic acid and glycolic acid; larger diameter yarns, colored in blue-PCA1 - or green-PCA2). The intensities of $\mathrm{R} 1 \& \mathrm{R} 2$ ratios and the amide $\mathrm{I}$ protein band is represented in false colors with a gradient from dark blue (low intensity) to hot red (high intensity). OM Optical microscopy, PCA1 \& PCA2 Principal Component Analysis 1 \& 2; R1 ratio: 1209/ $1180 \mathrm{~cm}^{-1}$ band intensity; R2 ratio: $1130 / 1080 \mathrm{~cm}^{-1}$ band intensity; Amide I protein band at $1646 \mathrm{~cm}^{-1}$
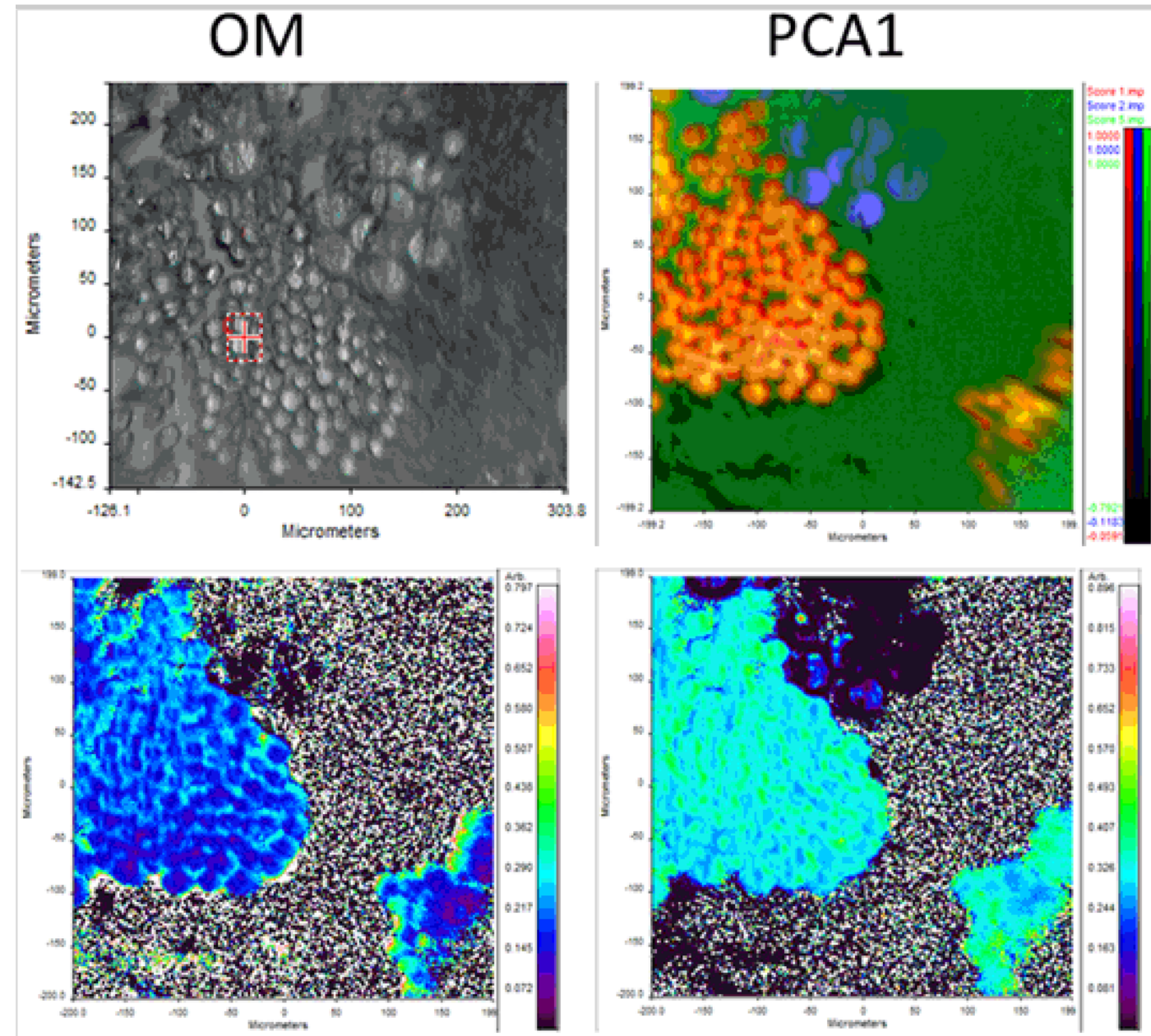

R1 ratio

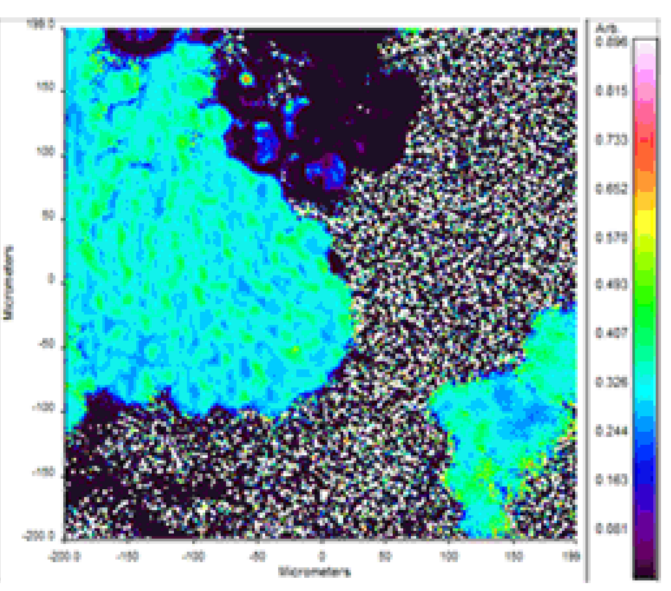

$\mathrm{R} 2$ ratio

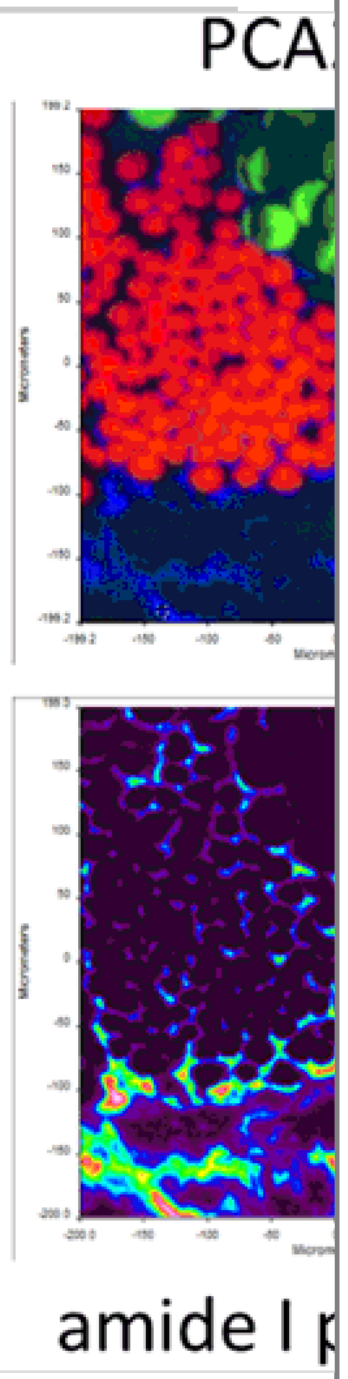


FTIR mappings of TIGR meshes at different degradation stages were then performed to evaluate the potential of this method to monitor the slow resorbing fibers degradation (Fig. 6). Four weeks after implantation, the PLA-based fibers of native ${ }_{0}$ TIGR samples were still easily visible on both OM pictures and PCA (PCA 1) maps. However, PCA maps exhibited not only fibers perpendicular to the section plan but also some that seemed to be parallel to this plan and were thus hardly identified on the OM pictures. It can be noticed that these parallel fibers were difficult to distinguish from other components on R2 ratio maps, which hindered the reading of their degradation state. This highlights the importance of the cutting plane compared to the multifilament yarns direction. Concerning the fibers that were perpendicular to the section plane, they apparently underwent bulk degradation as described in literature [34] and possibly followed the same degradation scheme as PLLA fibers since the inner part of the fibers seemed slightly more degraded. This observation however has to be taken carefully because fibers in TIGR meshes are much thinner than those in PLLA samples and resolution of the mapping may limit the accuracy of information provided on the crystallinity gradient. Moreover, amide I protein mapping revealed an important cell and ECM infiltration within the multifilament yarn structure between the fibers, higher than with PLLA samples after the same implantation time which could be explained by the thinner fibers and the textile structure of this device whose higher porosity stimulated cell proliferation and tissue colonization. Hence, the presence of ECM protein between the fibers may have induced misinterpretations from R2 ratio maps and no conclusion about auto-catalyzed degradation should be drawn.

\section{Fig. 6}

FTIR microscopy of non-pre-degraded TIGR mesh ( ${ }_{0}$ TIGR) and slightly predegraded TIGR mesh ( ${ }_{1}$ TIGR) explants, at 4 \& 26 weeks, after subcutaneous implantation, in rabbits. See Fig. 5 for the legends 

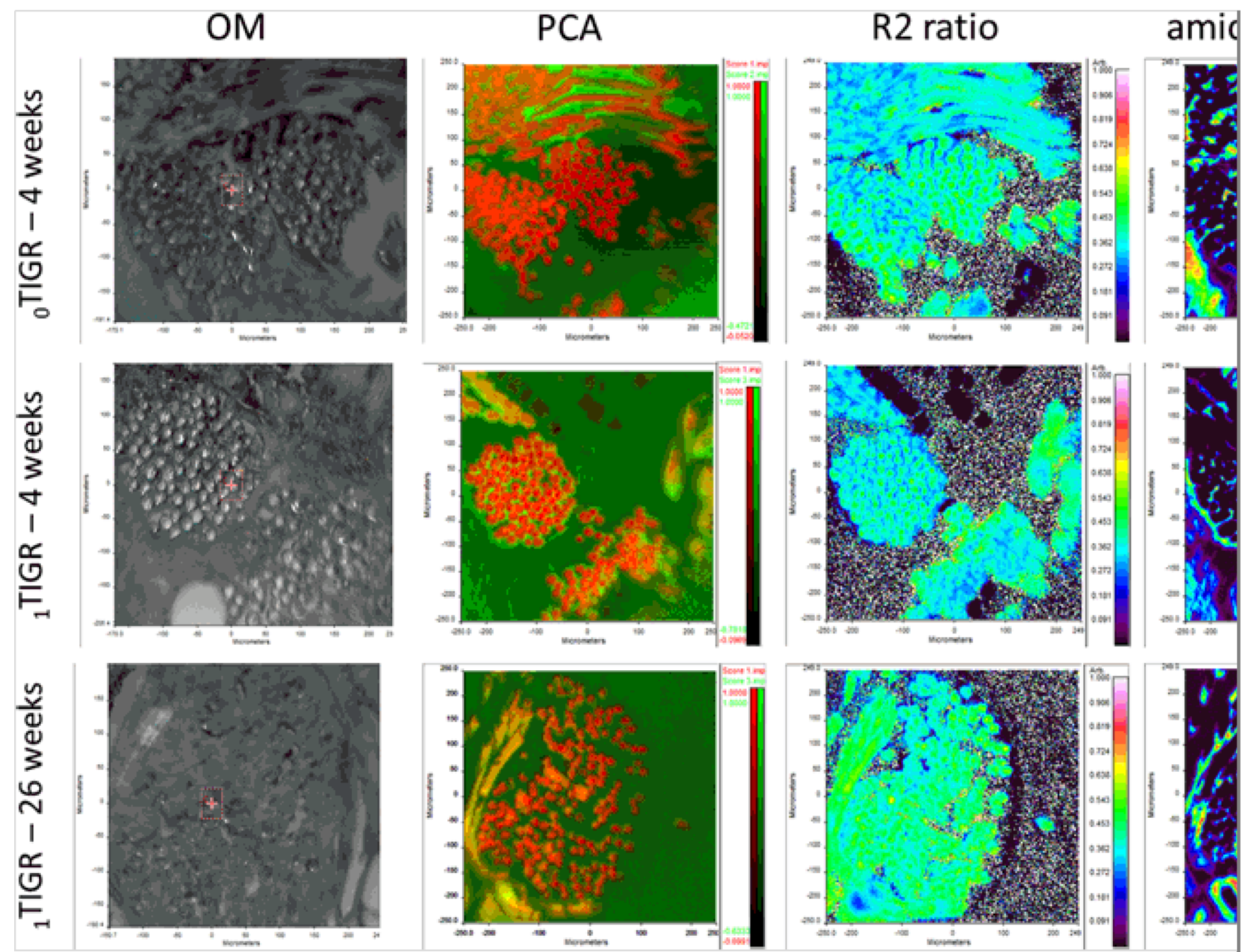

The analysis of FTIR mappings of pre-degraded ${ }_{1}$ TIGR 4 weeks after implantation led to the same observations as for ${ }_{0}$ TIGR. Slow resorbing fibers were indeed still visible on OM pictures and PCA maps, apparently followed a bulk degradation process and seemed to be at the same degradation stage, probably because the implantation time was too short to have an actual stronger impact on the degradation state. ECM deposition within the textile structure was also observed, which should once again prompt to remain cautious about drawing conclusions from $\mathrm{R} 2$ ratio maps.

After 26 weeks of in vivo degradation, slow resorbing fibers of ${ }_{1}$ TIGR samples were still visible but more difficult to distinguish from the surrounding tissues. Even though it was still possible to discern the shape of the fiber bundle on the PCA map, the fibers seemed smaller and more dispersed. On the opposite, the structure visible on the $\mathrm{R} 2$ ratio map appeared denser with larger stains than with PCA mapping. This difference could be explained by the important ECM infiltration around the fibers observed by protein mapping. Once again, the combined observation of the different mapping techniques was necessary to obtain reliable information. In this case, it was still possible to locate the fibers but not to have a precise idea of their degradation state because of the presence of neo-tissue ECM which blurred the polymer signal on the R2 ratio map. 
Likewise, no reliable picture could be obtained from even more degraded samples (data not shown) because of high polymer fragmentation and tissue infiltration.

\section{Discussion}

The aim of this study was to evaluate the potential of a novel imaging technique for identification of the implanted material and the degradation monitoring of bioresorbable polymers with special attention paid to PLLA. This technique is mainly based on the progressive changes which were observed on FTIR spectra of PLLA (at 1209 and $1130 \mathrm{~cm}^{-1}$ ) during in vitro degradation and were attributed to the evolution of $\alpha$ crystal formation, resulting of the structure rearrangement from chain scissions and increased mobility. Firstly, R1 and R2 peaks intensity ratios (1209/1180 and $1130 / 1080 \mathrm{~cm}^{-1}$ respectively) were used to verify this hypothesis. Non degraded PLLA samples with identical chemical compositions but different crystallinity rates were obtained by applying different thermal treatments (both samples were melt, the first one was then slowly cooled to allow crystallization whereas the other one was quenched in liquid nitrogen to obtain an amorphous polymer sample). When used on these samples, R1 and R2 ratios calculation exhibited the same trend as observed in the in vitro degradation study. In both cases, an increase of these ratios was indeed observed with the crystallinity rate, which proved that (i) the change of R1 and R2 ratios values reflected the degradation state of the polymer samples and (ii) the evolution of these values resulted from changes in crystallinity rate and not in chemical composition. This was the first step to demonstrate the potential of this technique prior to working on actual explanted devices.

Mappings were then realized on PLLA samples which were submitted to different in vitro and in vivo degradation times. A combined analysis of $\mathrm{OM}$ pictures and FTIR mappings (PCA, R2 ratio, and amide I protein), obtained by the single Infra-Red microscopic observations of tissue sections allowed us to clearly identify the implanted material even at a fragmented state and to monitor the state of the PLLA fibers after implantation (only R2 ratio was selected to prevent interactions with protein peaks). It appeared that $\mathrm{OM}$ pictures used alone provided only limited information for this purpose, including location of the fibers and potential observation of their fragmentation in best cases. On the opposite, the association of the three FTIR mapping techniques led to further more precise interpretations. PCA mapping allowed much more precise location and visualization of the fibers in the tissue sections. R2 ratio mapping provided information on the crystallinity change of the PLLA fibers, which is directly related to the progress of their degradation state. Resolution of the maps was sufficient to observe degradation gradients within single fibers, showing that 
they had undergone faster inner degradation, which was consistent with the described degradation mechanism involving bulk hydrolysis with autocatalysis [35]. Amide I protein mapping revealed the presence of ECM [36]. It is indicative of neo-tissue colonization of the implants, at least when it was detected within their structure, at advanced stages of degradation associated with implant fractures. Taken separately, each of these pictures thus provided information on the location of the PLLA fibers in the tissues, their fragmentation and degradation state and finally on the neo-tissue deposition. Nevertheless, complete and reliable interpretation required the analysis of these pictures taken all together. Pictures of the most degraded samples perfectly illustrated this necessity since they showed that an extensive presence of ECM proteins would interfere with the polymer peaks and make wrong signals appear on R2 ratio maps. Even though monitoring of the PLLA device was possible and reliable during a large period, a cautious study of the three different FTIR mappings together was essential to determine the limit time point up to which this technique should be used and trusted.

In order to see if this technique could be applied to other bioresorbable polymers, namely copolymers of lactic acid and other polyesters, a similar in vivo degradation protocol was used on another medical device, the TIGR matrix which is composed of two parts: slow resorbing fibers (copolymers of LA, GA and TMC) and fast resorbing fibers (copolymer of GA and TMC). In this specific case of multi-material device, characterization by FTIR mapping could be even more interesting since PCA mapping enabled the different components (ECM, fast resorbing and slow resorbing fibers) to be clearly identified at early degradation stages. It was thus possible to observe the morphology of the two kinds of fibers separately as long as the fast resorbing fibers were present. Moreover, the presence of LA in the slow resorbing fibers allowed the monitoring of their crystallinity and degradation state using R2 ratio mapping and evolution, just like it was done for PLLA samples. A precise evaluation of the degradation was however more difficult to obtain than with PLLA because of the low thickness of the fibers compared to the resolution of the mapping and because the textile structure allowed higher tissue deposition whose ECM proteins generated false signals on R2 ratio maps. Like for PLLA, FTIR mapping thus appeared to be a useful tool to follow the degradation and the integration of TIGR meshes after implantation, by following up the changes of the FTIR spectrum and specific peaks. Once again, only a careful FTIR combination of the different components, taken together (i.e. ECM, fast resorbing and slow resorbing fibers), but obtained from a single FTIR microscopy view, could lead to reliable information and interpretations. 


\section{Conclusion}

This study showed the value of an original technique to evaluate the evolution of resorbable polymers-based medical devices after implantation which is mandatory for any new commercial clinical implants. The novelty of this work lies in the association of the degradation state mapping of the polymers (based on the measure of crystallinity using specific FTIR peaks) with other already existing FTIR mappings (PCA and amide I protein peak) to get various valuable information: location of the materials, visualization of their morphology, comparative evaluation of their degradation state and assessment of their integration within the host tissues. This technique could be a very useful complement to current characterizations such as histological examination to judge the behavior of a resorbable medical device and the tissue response. If this concept was here demonstrated with PLA-based polymers, future developments on other resorbable polymers such as copolymers of lactic acid could be considered, as well as improvements of the process in order to reach semiquantitative measurements of the polymers degradation [37].

$\mathrm{AQ2}$

Electronic supplementary material

The online version of this article (doi:10.1007/s10856-017-5894-7) contains supplementary material, which is available to authorized users.

\section{Acknowledgements}

This work was partially supported by the Rhône-Alpes Region and the Fonds Unique Interministériel program (No AAP:15—Project No F1312025 V REVAMED).

Compliance with ethical standards

Conflicts of interest The authors declare that they have no competing interests.

\section{Electronic supplementary material}

Supplementary Data

Supplementary Figure 1 


\section{References}

1. Castillo RV, Müller AJ. Crystallization and morphology of biodegradable or biostable single and double crystalline block copolymers. Prog Polym Sci. 2009;34(6):516-60.

AQ3

2. Nair LS, Laurencin CT. Biodegradable polymers as biomaterials. Prog Polym Sci. 2007;32(8):762-98.

3. Garlotta D. A literature review of poly (lactic acid). J Polym Environ. 2001;9(2):63-84.

4. Saeidlou S, Huneault MA, Li H, Park CB. Poly (lactic acid) crystallization. Prog Polym Sci. 2012;37(12):1657-77.

5. Ikada Y, Tsuji H. Biodegradable polyesters for medical and ecological applications. Macromol Rapid Comm. 2000;21(3):117-32.

6. Zhou Q, Xanthos M. Nanoclay and crystallinity effects on the hydrolytic degradation of polylactides. Polym Degrad Stabil. 2008;93(8):1450-9.

7. Krikorian V, Pochan DJ. Crystallization behavior of poly (L-lactic acid) nanocomposites: nucleation and growth probed by infrared spectroscopy. Macromolecules. 2005;38(15):6520-7.

8. Grizzi I, Garreau H, Li S, Vert M. Hydrolytic degradation of devices based on poly (DL-lactic acid) size-dependence. Biomaterials. 1995;16(4):305-11.

9. Gorrasi G, Pantani R. Effect of PLA grades and morphologies on hydrolytic degradation at composting temperature: assessment of structural modification and kinetic parameters. Polym Degrad Stabil. 2013;98(5):100614.

10. Tsuji H, Ikada Y. Properties and morphology of poly (L-lactide) 4. Effects of structural parameters on long-term hydrolysis of poly (L-lactide) in phosphate-buffered solution. Polym Degrad Stabil. 2000;67(1):179-89.

11. Renouf-Glauser AC, Rose J, Farrar DF, Cameron RE. The effect of crystallinity on the deformation mechanism and bulk mechanical properties 
of PLLA. Biomaterials. 2005;26(29):5771-82.

12. $\mathrm{Xu} \mathrm{L,} \mathrm{Crawford} \mathrm{K,} \mathrm{Gorman} \mathrm{CB.} \mathrm{Effects} \mathrm{of} \mathrm{temperature} \mathrm{and} \mathrm{pH}$ on the degradation of poly (lactic acid) brushes. Macromolecules. 2011;44(12):477782.

13. Li S. Hydrolytic degradation characteristics of aliphatic polyesters derived from lactic and glycolic acids. J Biomed Mater Res. 1999;48(3):34253.

14. Oliveira M, Santos E, Araújo A, Fechine GJ, Machado AV, Botelho G. The role of shear and stabilizer on PLA degradation. Polym Test. 2016;51:10916.

15. Li MX, Kim SH, Choi SW, Goda K, Lee WI. Effect of reinforcing particles on hydrolytic degradation behavior of poly (lactic acid) composites. Composites Part B. 2016;96:248-54.

16. Partini M, Pantani R. Determination of crystallinity of an aliphatic polyester by FTIR spectroscopy. Polym Bull. 2007;59(3):403-12.

17. Tsuji H, Eto T, Sakamoto Y. Synthesis and hydrolytic degradation of substituted poly (DL-lactic acid)s. Materials. 2011;4(8):1384-98.

18. Tsuji H. Autocatalytic hydrolysis of amorphous-made polylactides: effects of L-lactide content, tacticity, and enantiomeric polymer blending. Polymer (Guildf). 2002;43(6):1789-96.

19. Li S, McCarthy S. Further investigations on the hydrolytic degradation of poly (DL-lactide). Biomaterials. 1999;20(1):35-44.

20. Lostocco MR, Huang SJ. The hydrolysis of poly (lactic acid)/poly (hexamethylene succinate) blends. Polym Degrad Stabil. 1998;61(2):225-30.

21. Maitz MF. Applications of synthetic polymers in clinical medicine. Biosurf Biotribol. 2015;1(3):161-76.

22. Schliecker G, Schmidt C, Fuchs S, Kissel T. Characterization of a homologous series of D, L-lactic acid oligomers; a mechanistic study on the degradation kinetics in vitro. Biomaterials. 2003;24(21):3835-44. 
23. Cheung HY, Lau KT, Lu TP, Hui D. A critical review on polymer-based bio-engineered materials for scaffold development. Composites Part B. 2007;38(3):291-300.

24. De Santis F, Pantani R, Titomanlio G. Nucleation and crystallization kinetics of poly (lactic acid). Thermochim Acta. 2011;522(1):128-34.

25. Migliaresi C, De Lollis A, Fambri L, Cohn D. The effect of thermal history on the crystallinity of different molecular weight PLLA biodegradable polymers. Clin Mater. 1991;8(1-2):111-8.

26. Pan P, Yang J, Shan G, Bao Y, Weng Z, Cao A, et al. Temperaturevariable FTIR and solid-state 13C NMR investigations on crystalline structure and molecular dynamics of polymorphic poly (L-lactide) and poly (L-lactide)/poly (D-lactide) stereocomplex. Macromolecules. 2011;45(1):18997.

27. Fischer EW, Sterzel HJ, Wegner GKZZ. Investigation of the structure of solution grown crystals of lactide copolymers by means of chemical reactions. Kolloid-Zeitschrift und Zeitschrift für Polymere. 1973;251(11):98090.

28. Middleton JC, Tipton AJ. Synthetic biodegradable polymers as orthopedic devices. Biomaterials. 2000;21(23):2335-46.

29. Lyu S, Schley J, Loy B, Lind D, Hobot C, Sparer R, Untereker D. Kinetics and time- temperature equivalence of polymer degradation. Biomacromolecules. 2007;8(7):2301-10.

30. Urayama H, Moon SI, Kimura Y. Microstructure and thermal properties of polylactides with different L-and D-unit sequences: importance of the Helical nature of the L-sequenced segments. Macromol Mater Eng. $2003 ; 288(2): 137-43$.

31. Zhang J, Duan Y, Sato H, Tsuji H, Noda I, Yan S, Ozaki Y. Crystal modifications and thermal behavior of poly (L-lactic acid) revealed by infrared spectroscopy. Macromolecules. 2005;38(19):8012-21.

32. Kister G, Cassanas G, Vert M. Effects of morphology, conformation and configuration on the IR and Raman spectra of various poly (lactic acid) s. Polymer (Guildf). 1998;39(2):267-73. 
33. He Y, Inoue Y. Novel FTIR method for determining the crystallinity of poly ( $\varepsilon$-caprolactone). Polym Int. 2000;49(6):623-6.

34. Hjort H, Mathisen T, Alves A, Clermont G, Boutrand JP. Three-year results from a preclinical implantation study of a long-term resorbable surgical mesh with time-dependent mechanical characteristics. Hernia. 2012;16(2):191-7.

35. Anderson JM, Shive MS. Biodegradation and biocompatibility of PLA and PLGA microspheres. Adv Drug Deliv Rev. 2012;64:72-82.

36. Liu KZ, Jackson M, Sowa MG, Ju H, Dixon IM, Mantsch HH. Modification of the extracellular matrix following myocardial infarction monitored by FTIR spectroscopy. Biochim Biophys Acta. 1996;1315(2):73-7. 